\title{
Induction of gp120-specific protective immune responses by genetic vaccination with linear polyethylenimine-plasmid complex
}

\author{
Manolo Rodrigo Garzón ${ }^{\mathrm{a}, 1}$, Pedro Berraondo ${ }^{\mathrm{a}, 1}$, Julien Crettaz ${ }^{\mathrm{a}}$, Laura Ochoa ${ }^{\mathrm{a}}$, Maria Vera ${ }^{\mathrm{a}}$, \\ Juan Jose Lasarte ${ }^{\mathrm{a}}$, Africa Vales ${ }^{\mathrm{a}}$, Nico Van Rooijen ${ }^{\mathrm{b}}$, Juan Ruiz ${ }^{\mathrm{a}}$, Jesús Prieto ${ }^{\mathrm{a}}$, \\ Javier Zulueta ${ }^{\mathrm{a}}$, Gloria González-Aseguinolaza ${ }^{\mathrm{a}, *}$ \\ ${ }^{a}$ Laboratory of Gene Therapy of Viral Hepatitis, Division of Hepatology and Gene Therapy, Clinica Universitaria/School of Medicine, Center for Applied \\ Medical Research (CIMA), University of Navarra, Pio XII 55, 31080 Pamplona, Spain \\ ${ }^{\mathrm{b}}$ Department of Cell and Immunology, Faculty of Medicine, Vrije Universiteit Medical Center, Van de Boechhorstatraat 7 , \\ 1081 BT Amsterdam, The Netherlands
}

Received 30 January 2004; received in revised form 13 August 2004; accepted 10 September 2004

Available online 6 October 2004

\begin{abstract}
The induction of IFN- $\gamma$-secreting CD8+ T cells and neutralizing antibodies to HIV-1 are both key requirements for prevention of viral transmission and clearance of pathogenic HIV. Although DNA vaccination has been shown to induce both humoral and cellular immune responses against HIV antigens, the magnitude of the immune responses has always been disappointing. In this report, we analyze the ability of polyethylenimine (PEI)-DNA complex expressing an HIV-glycoprotein 120 (gp120) antigen (PEI-pgp120) to induce systemic CD8+ T cell and humoral responses to the gp120 antigen. The administration of PEI-plasmid complex resulted in rapid elevation of serum levels of IL-12 and IFN- $\gamma$. Furthermore, a single administration of PEI-pgp120 complex elicits a number of gp120-specific CD8+ T cells 20 times higher than that elicited by three intramuscular injections of naked DNA. Interestingly, we found that systemic vaccination with PEI-pgp120 induced protective immune responses against both systemic and mucosal challenges with a recombinant vaccinia virus expressing a gp120 antigen. The data also demonstrated that the depletion of macrophages with liposome-encapsulated clodronate completely abolished gp120-specific cellular response. Overall, our results showed that a single administration of PEI-pgp120 complexes, eliciting strong immune responses, is an effective vaccination approach to generate protection against systemic and mucosal viral infections.
\end{abstract}

(c) 2004 Elsevier Ltd. All rights reserved.

Keywords: Polyethylenimine; Plasmid DNA; HIV-gp120; CD8+ T cell; Protection

\section{Introduction}

An optimal acquired immunodeficiency syndrome (AIDS) vaccine should be able to induce both envelope glycoprotein 120 (gp120)-specific neutralizing antibodies, as well as systemic and mucosal cellular immune responses to human

\footnotetext{
Abbreviations: PEI, polyethylenimine; gp120, glycoprotein 120; HGH, human growth hormone

* Corresponding author. Tel.: +34 948 425600x6345; fax: +34 948425700

E-mail address: ggasegui@ unav.es (G. González-Aseguinolaza).

${ }^{1}$ Contributed equally to this work.
}

immunodeficiency virus (HIV)-infected cells [1-7]. Vaccine strategies which elicit potent cytotoxic $\mathrm{T}$ cell (CTL) responses lead to reduced virus loads and long-term protection against immunodeficiency disease in macaque challenge studies using simian immunodeficiency virus (SIV) or pathogenic simian-human immunodeficiency virus chimeras (SHIV) [8,9]. It has been recently reported that viral escape from CTL recognition can result in the eventual failure of the immune protection induced by candidate AISD vaccines [10] and rhesus macaques infected with SIV/SHIV show significantly higher viral loads if CD8+ T cells are eliminated $[11,12]$. Glycoprotein 120 by itself is weakly immunogenic and immunizations with plasmid DNA encoding gp120 alone 
are not efficient. DNA immunizations with gp120 of HIV usually require boosting with viral vaccines, co-administration of various cytokines or expression as a fusion protein with proinflammatory chemoattractants to achieve optimal efficacy [13-17].

The ability of plasmid DNA to induce both humoral and cellular immune responses against a variety of infectious agents has been well documented [18]. Numerous scientific publications have reported the effectiveness of DNA vaccines in providing potent immune responses or protective immunity against viruses, bacteria and parasites in several species including human volunteers [19-21]. DNA vaccination has become an accepted method in the research community, and is now being tested on humans. Although safety and efficacy have been demonstrated, the potency of the immune response against the antigens induced by plasmid immunization compared with the use of viral vectors has been disappointing [22]. The main problem associated with DNA administration is the low efficiency of cellular uptake and expression in vivo. A number of different strategies are being developed to increase the efficacy of DNA vaccines. The development of appropriate vehicles that increase plasmid transfection and protect from degradation in the biological environment is one of the strategies being examined. Production of DNA complexes with polycations is being widely studied as a strategy to improve DNA immunization protocols [23].

The cationic polymer, polyethylenimine (PEI), is known to be an efficient carrier of DNA that promotes uptake by and transfection of cells in vitro [24]. It appears to work by compacting DNA into particles by way of electrostatic interactions, thereby protecting the DNA from enzymatic degradation and providing a global positive charge, which facilitates uptake by cells [25]. The ability of PEI to act as an efficient vector for DNA transfer resides also in its capacity to permeabilize the endosomal membranes, thus providing the DNA with access to the cytoplasm. Although the mechanism for PEI-mediated transfection is not fully understood, there is evidence that PEI and PEI-DNA complexes undergo nuclear localization more effective than cationic lipids [25]. A number of PEI molecules have been described with varying molecular sizes and structures-among them, branched PEI with an average molecular weight of $800 \mathrm{kDa}$ (PEI800) or $25 \mathrm{kDa}$ (PEI25), and linear forms with an average molecular weight of $22 \mathrm{kDa}$ (PEI22) — have been widely used and characterized both in vivo and in vitro [26]. In vivo, systemically delivered PEI22-DNA complexes resulted in the transduction of the lung, spleen, liver, heart and kidney, with no histological change observed in these organs [27]. PEI22-DNA complexes can repeatedly be administered to animals without eliciting an immune response against the polymer, although the development of an immune response against the exogenously expressed protein has been reported to reduce the level of protein expression [28]. In fact, administration of lungtargeted macroaggregated polyethylenimine-albumin conjugates expressing human growth hormone (HGH) has been shown to elicit a humoral immune response against the $\mathrm{HGH}$ [29].

In this report, we seek to develop a simple AIDS vaccine strategy using a particulate gene delivery system formed through non-covalent complexation of PEI and a DNA plasmid expressing HIV-gp120 antigen. We demonstrate that administration of these complexes generates significantly more IFN- $\gamma$-secreting gp120-specific CD8+ T cells than naked DNA vaccines expressing gp120. Although the PEI-DNA vaccine was systemically delivered, protection was observed against both systemic and mucosal challenges with a recombinant vaccinia virus. We also show that PEI-DNA-induced immune response depends on the activation of macrophages.

\section{Materials and methods}

\subsection{Experimental animals}

Female, 5-6-week-old, BALB/c mice were obtained from Taconic Laboratories and maintained according to the regulations of our institution. All mice were acclimatized for 1 week before immunization. Prior to immunization, mice were bled orbitally and sera were collected for subsequent enzyme-linked immunosorbent assay (ELISA).

\subsection{Plasmid DNA}

The gp120 gene under the control of the human cytomegalovirus (CMV) promoter/enhancer was a gift from Dr. M. Esteban and Dr. D. Rodríguez. The plasmids were produced and purified using reagents and columns for endotoxinfree DNA (Quiagen, Valencia, CA) and then dissolved in an endotoxin-free 5\% glucose solution to the desired concentration. The plasmids were predominantly supercoiled and were quantitated using UV absorbance. The recombinant VVgp120 employed in this study was provided by Dr. M. Esteban and Dr. D. Rodríguez. The virus was grown in human HeLa cells, and sucrose cushion purified virus was titrated in African green monkey kidney BSC-40 cell monolayers by plaque assays.

\subsection{Preparation of PEI/DNA complexes}

The desired amount of DNA in a solution of 5\% glucose (water containing 5\% glucose) was complexed with PEI $22 \mathrm{kDa}$ by adding the DNA to the PEI while vigorously vortexing the solution. The solution was then allowed to incubate at room temperature for $15 \mathrm{~min}$ prior to animal administration. PEI/DNA complexes were formed at a molar ratio of PEI nitrogen to DNA phosphate of 4 (nitrogen/phosphate $(\mathrm{N} / \mathrm{P})=4)$.

\subsection{Immunization protocol}

PEI-DNA complexes were injected intravenously as a single $400 \mu \mathrm{l}$ volume via the tail vein. Animals were kept under 

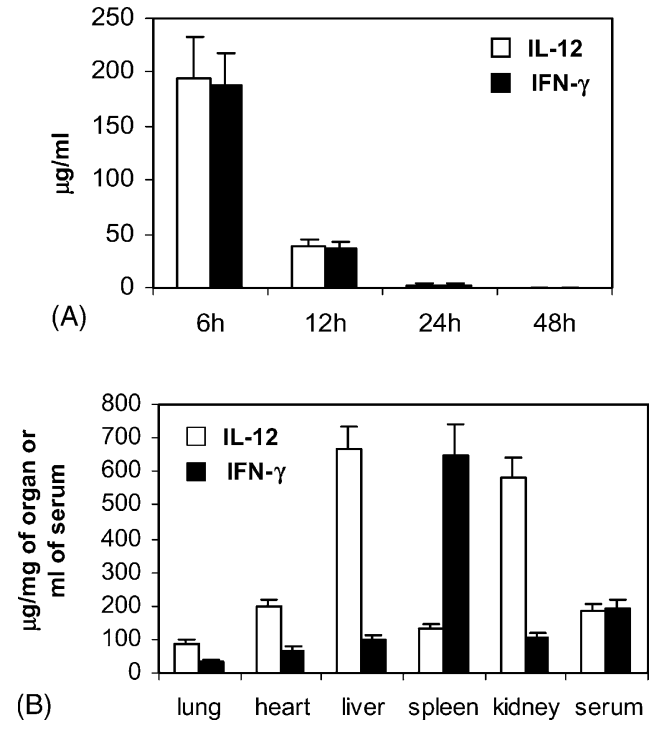

Fig. 1. Effect of i.v. administration of PEI-plasmid complexes on the IL-12 and IFN- $\gamma$ production in serum and in different organs. Groups of BALB/c mice $(n=6)$ were injected via tail vein with $100 \mu \mathrm{g}$ of PEI-pluciferase complexes at an amine over phosphate ratio of 4 in $400 \mu 15 \%$ glucose. (A) From a group of five mice, serial blood samples were obtained and the total amounts of IL-12 and IFN- $\gamma$ in the serum were assayed by ELISA. Results displayed are means of total cytokine quantity. (B) A second group of five mice were sacrificed $6 \mathrm{~h}$ after injection and the lungs, liver, kidney, heart, spleen from each mouse were excised, the organs were homogenized in RIPA buffer and assessed individually for the expression of IL-12 and IFN- $\gamma$. Results displayed are means of cytokine quantity per $\mathrm{mg}$ of organ or $\mathrm{ml}$ of serum.

observation for $1 \mathrm{~h}$ after intravenous administration. In the experiment shown in Fig. 1, mice received $100 \mu \mathrm{g}$ of a plasmid expressing luciferase under the control of a CMV promoter complexed with PEI $22 \mathrm{kDa}$ at N/P of 4 . In experiment shown in Fig. 2A, mice received different doses of pgp120 plasmid, from 5 to $150 \mu \mathrm{g}$ complexed with PEI $22 \mathrm{kDa}$ at N/P of 4 . In the experiment shown in Fig. 2B, mice received $100 \mu \mathrm{g}$ of pgp120 plasmid complexed with PEI $22 \mathrm{kDa}$ or alone. Mice intramuscularly immunized with naked DNA received three doses of $100 \mu \mathrm{g}$ of pgp120 suspended in $100 \mu \mathrm{l}$ PBS every 2 weeks. Control mice were injected with $100 \mu \mathrm{l}$ PBS containing $100 \mu \mathrm{g}$ luciferase coding vector DNA.

\subsection{Quantification of epitope specific CD8+T cells by ELISPOT assay}

We determined the number of CD8+ T cells that recognized HIV antigen in immunized mice by obtaining splenocytes from these mice, and stimulating them with the MHCcompatible target cells P815 incubated with $1 \mu \mathrm{M}$ of p18 peptide (RIQRGPGRAFVTIGK) for $1 \mathrm{~h}$ at $37^{\circ} \mathrm{C}$. This peptide contains the $\mathrm{H}-2^{\mathrm{d}}$ restricted $\mathrm{CD} 8+\mathrm{T}$ cell epitope corresponding to the V3 loop of HIV strain IIIB. Two weeks after immunization, mice were sacrificed and single-cell suspensions were prepared from the spleen. Ninety-six-well nitrocellulose plates (Multiscreen HA, Millipore Corp., Bedford, MA) were coated with anti-mouse IFN- $\gamma$ mAb, R4. After
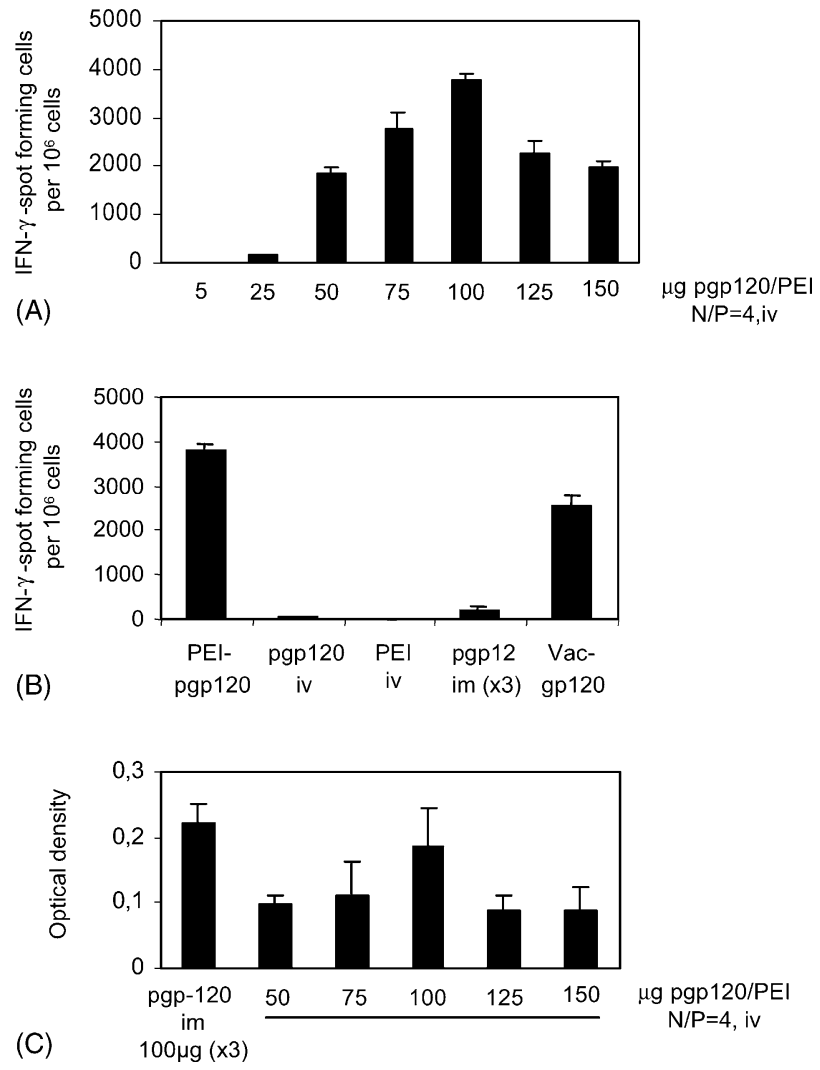

Fig. 2. gp120-specific cellular and humoral immune response in BALB/c mice using different immunization protocols. (A) Groups of three BALB/c mice were immunized i.v. with different doses of PEI-pgp120 complexes $(\mathrm{N} / \mathrm{P}=4)$ from 5 to $150 \mu \mathrm{g}$ in a volume of $400 \mu \mathrm{l}$, and 2 weeks later, splenic lymphocytes were isolated and the number of IFN- $\gamma$-secreting p18-specific CD8+ T cells was determined by an ELISPOT assay. (B) Groups of three $\mathrm{BALB} / \mathrm{c}$ mice were immunized with a single dose of $100 \mu \mathrm{g}$ of PEI-pgp120 complexes in a volume of $400 \mu \mathrm{l}, 400 \mathrm{ml}$ of a solution of PEI $10 \mathrm{mM}$ diluted in 5\% glucose, $100 \mu \mathrm{g}$ of pgp120 administered i.v. in a volume of $400 \mu \mathrm{l}$ of $5 \%$ glucose, i.p. with $5 \times 10^{7}$ PFU of Vac-gp120, or three doses of $100 \mu \mathrm{g}$ of pGp120 i.m. administered. Two weeks later, splenic lymphocytes were isolated and the number of IFN- $\gamma$-secreting p18-specific CD8+ T cells was determined by an ELISPOT assay. (C) Serum samples obtained from the groups of mice in (A) 2 weeks after last immunization and the presence of anti-gp120 antibodies was measured by antigen-specific ELISA. Mean optical densities $( \pm$ S.D.) for each group are shown for a serum dilution of 1:100, with the background OD of wells with serum from non-immunized mice subtracted.

overnight incubation at room temperature, the wells were washed and incubated with the medium for $3 \mathrm{~h}$ at $37^{\circ} \mathrm{C}$. Targets cells not pulsed with the peptide or pulsed with an irrelevant CD8+ epitope from hepatitis B core antigen were used as negative controls. Serially diluted lymphocytes, starting at $1 \times 10^{6}$ cells per well, were co-cultured with $1 \times 10^{5}$ target cells in the ELISPOT wells. After incubating the plates for $24 \mathrm{~h}$ at $37^{\circ} \mathrm{C}$ and $5 \% \mathrm{CO}_{2}$, the plates were treated as previously described [30] and the number of spots corresponding to IFN- $\gamma$ secreting cells determined. The background level, namely the number of cells which secrete IFN- $\gamma$ in the absence of antigen, was subtracted in every experimental group. 


\section{6. gp120-antibody measurements by ELISA}

High-binding polystyrene microtiter plates (MaxisorpTM; Nunc A/S, Roskilde, Denmark) were coated with $100 \mu \mathrm{l}$ of the peptide $2 \times$ RIQRGPGRAFVTIGK at $20 \mathrm{mg} / \mathrm{ml}$ in $0.05 \mathrm{M}$ carbonate-bicarbonate buffer $\mathrm{pH}$ 9.6 overnight at $4{ }^{\circ} \mathrm{C}$. The wells were washed twice with $0.05 \%$ Tween-20 in PBS (PBS-T) and blocked with PBST containing $1 \%$ no-fat dry milk for $1 \mathrm{~h}$ at room temperature. Serum samples diluted in blocking solution were added in a volume of $100 \mu \mathrm{l} /$ well and incubated for $1 \mathrm{~h}$ at RT. Plates were washed six times before the detection antibody was added: peroxidase-conjugated rabbit antimouse immunoglobulin G (IgG) antibody (Sigma, St. Louis, MO) diluted 1:5000 in blocking solution and incubated for $1 \mathrm{~h}$ at RT. After being washed six times with PBS-T and three times with PBS, the plates were developed with 2,2'-azinobis(3-ethylbenzthiazolinesulfonic acid) (ABTS) peroxidase substrate. After $10 \mathrm{~min}$ incubation, plates were read at $405 \mathrm{~nm}$ on a plate reader. Mean optical densities $( \pm$ S.D.) for each group were obtained at a serum dilution of 1:100, with the background OD of wells with serum from non-immunized mice subtracted.

\subsection{IL-12 and IFN- $\gamma$ ELISA}

Levels of IL-12 and IFN- $\gamma$ were determined in serum and in the different organ samples of mice by using a cytokine enzyme-linked immunosorbent assay kit (PharMingen, San Diego, California) according to the manufacturer's instructions. Organ samples for IL-12 and IFN- $\gamma$ assay were disintegrated in $500 \mu \mathrm{l}$ of ice-cold Ripa buffer. After incubation on ice for $30 \mathrm{~min}$, samples were centrifuged twice at 20,000 $\times \mathrm{g}$ for $15 \mathrm{~min}$ at $4{ }^{\circ} \mathrm{C}$ and the resulting supernatants were used for assay. The threshold of detection of the IFN- $\gamma$ and the IL-12 assay is 14 and $4 \mathrm{pg} / \mathrm{ml}$, respectively.

\subsection{In vivo protection against infection with a recombinant vaccinia virus expressing gp120}

Two weeks after immunization with PEI-pgp120 complex, mice were challenged intraperitoneally with $5 \times 10^{7}$ PFU of the recombinant vaccinia virus expressing gp120. Five days after vaccinia challenge, mice were sacrified and ovaries and lungs removed, homogenized, sonicated and assayed for virus titer by plating serial 10-fold dilutions of samples on a plate of BSC-1 indicator cells. After 2 days of culture, cells were stained with crystal violet to detect PFU at each serial dilution. For quantitative real time PCR titering, viral DNA from the homogenized ovaries and lungs were extracted using the High Pure Viral Nucleic Acid Kit (Boehringer Mannheim), according to manufacturer's instructions and then subjected to real time PCR. Primers and TaqMan probes (Applied Biosystems, Foster City, CA) for vaccinia virus hemaglutinin gene (GeneBank: AF375124) (sense: 5'-
TGACTACGTTGTTATGAGTGCTTGG-3', anti-sense: $5^{\prime}$ TTATCAAAATACAAGACGTCGCTTTT-3', probes: 5'AAGGAGCCCAATTCCATTATTCTTTTAG-3') designed using the Primer-Express software were used for the PCR. The reaction was performed in $20 \mu l$ with $2 \mu l$ of sample, $\mathrm{MgCl}_{2} 5 \mathrm{mM}, 0.3 \mu \mathrm{M}$ of each primer, $0.1 \mu \mathrm{M}$ of probe and $2 \mu \mathrm{l}$ of LightCycler-FastStart DNA Master Hybridizaton Probes (Roche Diagnostic GmbH, Mannheim, Germany). PCR was performed according to the following parameters: initial denaturation for $10 \mathrm{~min}$ at $95^{\circ} \mathrm{C}$, and 40 cycles of $10 \mathrm{~s}$ at $95^{\circ} \mathrm{C}$ and hybridization/elongation of $20 \mathrm{~s}$ at $60^{\circ} \mathrm{C}$ with a temperature transition rate of $20^{\circ} \mathrm{C} / \mathrm{s}$. The fluorescence signal delivered during PCR amplification was monitored using the LightCycler System (Roche Diagnostics, Basel, Switzerland). The copy number of vaccinia DNA in each sample was determined by interpolation, using an external standard consisting of serial dilutions $\left(10^{9}-10^{1}\right)$ of a plasmid containing the amplified fragment.

\subsection{Plasma AST and ALT}

The concentrations of aspartate aminotransferase (AST) and alanine aminotransferase (ALT) were measured in plasma samples with kits obtained from Sigma (St. Louis, MO) according to the manufacturer's protocol.

\subsection{Macrophage depletion}

Clodronate was a gift from Roche Diagnostics $\mathrm{GmbH}$ (Mannheim, Germany). Phosphatidylcholine (Lipoid E PC) (Lipoid GmbH, Ludwigshafen, Germany) and cholesterol (Sigma, St. Louis, MO) were used to prepare the liposomes as described earlier [31,32]. Mice were intravenously injected with $20 \mu \mathrm{l}$ per $10 \mathrm{~g}$ body weight of the standard suspension of clodronate liposomes diluted in PBS in a final volume of $50 \mu 1$.

\section{Results}

\subsection{Induction of immunostimulatory cytokine expression after intravenous administration of PEI-DNA complexes}

We first asked whether the administration of PEI-DNA complexes is able to induce an innate immune response as has been described for naked DNA [33]. For this purpose, two groups of five mice were injected intravenously with PEI-DNA complexes generated with $100 \mu \mathrm{g}$ of luciferaseor GFP-expressing plasmids together with PEI-22 $\mathrm{kDa}$ at N/P ratio of 4 in 5\% glucose solution. The same amount of PEI or DNA dissolved in 5\% glucose solution was injected into two groups of five mice as controls. Serum IL-12 levels were measured 6, 12, 24 and $48 \mathrm{~h}$ after the injection by ELISA. High levels of IL-12 $(180-200 \mu \mathrm{g} / \mathrm{ml})$ were detected $6 \mathrm{~h}$ after i.v. injection of PEI-pluciferase, decreasing to $2-3 \mathrm{ng} / \mathrm{ml} 24 \mathrm{~h}$ post injection, and finally disappearing at $48 \mathrm{~h}$ (Fig. 1A, data 
not shown). The analysis of IFN- $\gamma$ expression in the serum showed that as in the case of IL-12, the maximum level was obtained during the first $12 \mathrm{~h}$ after injection, with the level decreasing 100 times after $24 \mathrm{~h}$, although low levels of IFN$\gamma$ were maintained in the serum for a longer period of time ( $215 \mathrm{pg} / \mathrm{ml}, 72 \mathrm{~h})$ (Fig. 1A). Similar results were obtained in the group of mice that received PEI-pGFP complex, and no IL-12 or IFN- $\gamma$ was detected in the serum of mice that received PEI or DNA alone (data not shown).

We next analyzed IL-12 and IFN- $\gamma$ expression levels in different organs $6 \mathrm{~h}$ after i.v. injection of $100 \mu \mathrm{g}$ of PEI-pluciferase complex. As shown in Fig. 1B, the expression of both cytokines was detected in all the organs tested, including lung, kidney, liver, spleen and heart. We found high levels of IL-12 in the liver and kidney, whereas IFN- $\gamma$ has a different organ distribution with high levels of IFN- $\gamma$ found in the spleen (Fig. 1B). Surprisingly, low levels of IL-12 and IFN- $\gamma$ were detected in the organ that showed the highest transgene expression $6 \mathrm{~h}$ after PEI-pluciferase administration, the lung [34].

\section{2. gp120-specific CD8+ T cell response elicited by i.v. administration of PEI-DNA complexes expressing HIV-gp120 antigen}

To test whether PEI-DNA complexes could induce specific immune responses against a given antigen, increasing amounts (from 5 to $150 \mu \mathrm{g}$ of DNA) of PEI-pgp120 complexes at a N/P ratio of 4 in $400 \mu l 5 \%$ glucose were injected i.v. into five BALB/c mice per group (Fig. 2A). For comparative purposes, mice were also immunized i.m. with three doses of $100 \mu \mathrm{g}$ of pgp120 naked DNA, a single dose of $100 \mu \mathrm{g}$ of pgp120 naked DNA injected i.v. and a single i.p. dose of $5 \times 10^{7}$ of a recombinant vaccinia virus expressing gp120 (Fig. 2B). Spleen cells from the mice were obtained 2 weeks after immunization and the numbers of gp120specific IFN- $\gamma$-secreting CD8+ T cells were determined by an ELISPOT assay. Mice carrying $\mathrm{H}-2^{\mathrm{d}}$ haplotype, such as $\mathrm{BALB} / \mathrm{c}$ mice, generate CD8 $\mathrm{T}$ cell responses specific for an epitope (p18 epitope) within V3 loop of gp120, and the amino acid sequence is RIQRGPGRAFVTIGK. Therefore, the 18 peptide was incubated with P815 plasmacytoma cells, which were used for in vitro stimulation of splenocytes obtained from gp120-immunized mice. As shown in Fig. 2A, there was a dose-dependent, gp120-specific CD8+ T cell response, when the dose of the plasmid used was below $100 \mu \mathrm{g}$. However, when higher amounts of DNA were administered to the mice, the CD8+ $\mathrm{T}$ cell response was diminished. No gp120-specific response was observed in the spleen of mice immunized with PEI-pluciferase, a control immunogen (data not shown).

As shown in Fig. 2B, the relative number of gp120specific, IFN- $\gamma$-secreting CD8+ T cells obtained after a single i.v. immunization with $100 \mu \mathrm{g}$ of PEI-pgp120 was 20 times higher than that elicited after three i.m. immunizations with $100 \mu \mathrm{g}$ of pgp120 and similar to that elicited after a single i.p. immunization with a recombinant vaccinia virus expressing gp120. The differences found in the number of gp120specific, IFN- $\gamma$-secreting cells among the different vaccination strategies varied from one experiment to the other. However, the immunization with PEI-pgp120 complexes consistently resulted in a 20 -fold increase in gp120-specific IFN$\gamma$-secreting CD8+ T cells compared to the number of the $\mathrm{T}$ cells elicited after three i.m. immunizations with a naked DNA. The analysis of IL- 12 and IFN- $\gamma$ in the serum of mice, immunized from Fig. 2A, 6, 12, 24 and $48 \mathrm{~h}$ after the injection showed a dose-dependent expression of both cytokines (data not shown), with the same pattern of expression as described for PEI-pluc (Fig. 1A).

\subsection{Anti-gp120 antibody response elicited by i.v. administration of PEI-DNA complexes expressing HIV-gp120 antigen}

Sera from mice employed in the experiment described above were used to measure the titers of IgG antibodies specific for the V3 region of gp120 antigen. As shown in Fig. 2C, the antibody response was dose-dependent, with no antibody response being detected in the group of mice that received the lower doses $(5-25 \mu \mathrm{g})$, whereas the optimal antibody response was obtained in the group of mice that received $100 \mu \mathrm{g}$ of PEI-pgp120. Similarly to cellular response, the administration of the higher doses resulted in a lower antibody response.

The level of antibody response after a single i.v. administration of $100 \mu \mathrm{g}$ PEI-pgp120 was similar to that observed in the group of mice immunized i.m. with three doses of $100 \mu \mathrm{g}$ of naked DNA.

\subsection{Administration of PEI-gp120 complex protects animals against a systemic and mucosal challenge with recombinant vaccinia expressing gp120}

We have shown that PEI-DNA immunization induces both cellular and humoral immune responses against the antigen of interest. However, our ultimate goal is to induce a protective response against a viral challenge. Therefore, to test whether the PEI-DNA vaccination could induce a protective immune response against a viral infection, mice were immunized with $100 \mu \mathrm{g}$ of PEI-pgp120, followed by an intraperitoneal or intranasal challenge with $5 \times 10^{7} \mathrm{PFU}$ of a recombinant vaccinia virus expressing gp120 antigen (Vacgp120). Ten control mice received $100 \mu \mathrm{g}$ of PEI-luc. Five days after challenge, ovaries and lungs were removed from the mice, and the virus titers were measured by a sensitive quantitative PCR assay, as well as by conventional plaque assay method. Challenge experiments were replicated three times; Fig. 3 shows the results obtained in one representative experiment. In the ovaries of mice immunized with PEI-pluc, i.p. challenge showed viral titers higher than $10^{6} \mathrm{PFU}$. In contrast, no viral replication in the ovaries was observed in 8 out of 10 PEI-pgp120 immunized mice. Thus, $80 \%$ of immu- 


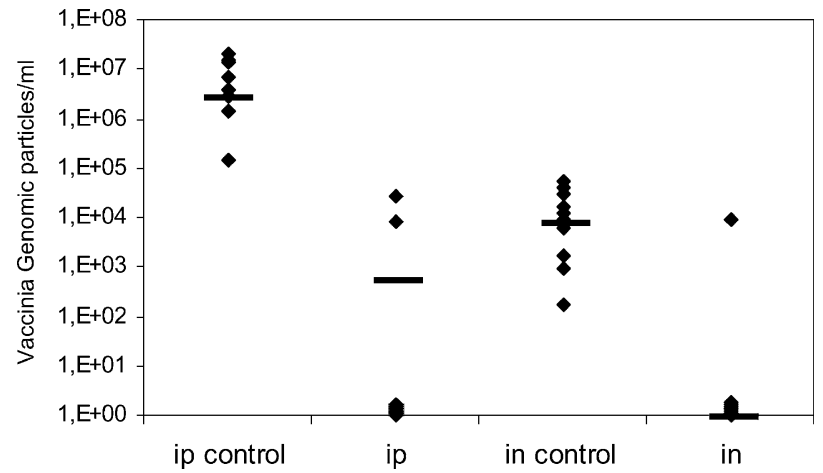

Fig. 3. Vaccinia virus titers in ovaries and lungs after intraperitoneal and intranasal challenge with Vac-gp120. Ten BALB/c mice per group were immunized with $100 \mu \mathrm{g}$ of PEI-pgp120 i.v.; 2 weeks later, immunized mice were challenged with $5 \times 10^{7} \mathrm{PFU}$ each of vaccinia virus encoding gp120 i.p. or i.n. As controls, mock-immunized mice were challenged with the same virus. The ovaries and lungs were harvested 5 days after challenge, and vaccinia virus titers were determined by quantitative PCR. Data are shown for each mouse, and the mean vaccinia titer is indicated.

nized mice were completely protected from vaccinia challenge, with no viral DNA detected in the ovaries. A similar result was obtained after i.n. challenge with the virus, with only 1 mouse out of 10 possessing vaccinia genome particles in the lungs, whereas control mice i.n. challenged with Vac-gp120 showed viral titers higher than $10^{4}$ PFU (Fig. 3).

The analysis of viral loads by the conventional plaque assay method gave similar results with a correlation index of 0.9253; however, the plaque assay was less sensitive, since some of the mice that were positive by the quantitative PCR assay were negative by plaque assay (data not shown).

\subsection{Toxicity}

The toxicity associated with i.v. administration of PEI-DNA complexes has been described as lung embolism and liver injury [34]. In order to assess the toxicity of our PEI-pgp120 complexes, we looked at the morbidity and mortality of injected mice, and measured biochemical parameters that indicate liver injury. More specifically, groups of five $\mathrm{BALB} / \mathrm{c}$ mice received different doses of PEI-pgp120 complexes intravenously, with control mice receiving the highest dose of PEI or DNA $(150 \mu \mathrm{g})$ dissolved in $5 \%$ glucose solution. As a positive control, a group of mice received a single injection of Concanavaline A (ConA), a compound that, in mice, rapidly leads to massive hepatocyte apoptosis, and consequent increases in serum transaminase levels [35].

Overall, we did not observe a lethal effect with our PEI-pgp120 complexes even at the highest dosage used in our experiments. The results of the serum levels of ALT and AST determined $6 \mathrm{~h}$ after vaccine administration are shown in Fig. 4. Intravenous administration of 125 and $150 \mu \mathrm{g}$ of PEI-pgp120, as well as ConA, resulted in significantly increased plasma levels of the transaminases, indicating a liver injury. No significant increases in transaminase levels were

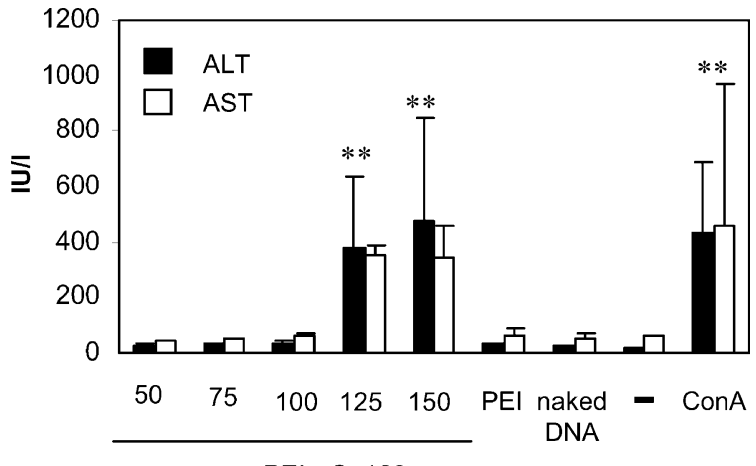

$\mu$ g PEI-pGp120

Fig. 4. Biochemical markers of liver injury. BALB/c mice received an i.v. injection of different doses of PEI-pGp120 (from 50 to $150 \mu \mathrm{g}$ ), PEI, $100 \mu \mathrm{g}$ of pGp120, or ConA. Biochemical markers of liver injury ALT $(\square)$, AST $(\square)$ were determined after $6 \mathrm{~h}$ in all the groups. A group of five naïve mice was used as control. UI, international units. $n=9-10$ mice/group. Means \pm standard errors. Significantly different from control $* * p<0.01$.

observed in the rest of the groups, suggesting that lower doses of the PEI-pgp120 complexes are non-toxic. Interestingly, the toxicity associated with the highest doses of PEI-pgp120 complexes correlates with the lower immune responses induced by these doses (Fig. 2A).

\subsection{Role of macrophages in the immune response induced by PEI-DNA complexes}

In mice, a single i.v. injection of clodronate liposomes results in the depletion of splenic and bone marrow macrophages and liver Kupffer cells $24 \mathrm{~h}$ after injection [31,32]. To test the influence of macrophages on the immune response induced by PEI-DNA complexes, clodronate liposomes were i.v. injected into BALB/c mice, and $24 \mathrm{~h}$ later, these as well as non-treated control mice received a single i.v. dose of $100 \mu \mathrm{g}$ PEI-pGp120 complexes. Six hours after DNA immunization, sera were collected from the mice, and the level of IL-12 measured. As shown in Fig. 5A, the depletion of macrophages prior to PEI-DNA immunization resulted in decreased serum levels of IL-12. We then measured the levels of gp120-specific $\mathrm{T}$ cell response by an ELISPOT assay in macrophage-depleted mice and non-depleted mice 2 weeks after DNA immunization. As shown in Fig. 5B, macrophagedepleted mice failed to mount a gp120-specific CD8+ T cell response. These results indicate that macrophages mediate the production of IL-12 in the sera and also the generation of an optimal antigen-specific CD8+ $\mathrm{T}$ cell response following PEI-DNA vaccination.

Furthermore, the analysis of transaminase levels (ALT, AST) $6 \mathrm{~h}$ after the PEI-DNA complex immunization revealed that non-depleted mice showed normal transaminase levels, whereas macrophage-depleted mice showed an increase in transaminase levels (Fig. 5C). Thus, macrophages may act as a first-line barrier in the liver, by capturing PEI-DNA complexes and preventing PEI-DNA-induced death of hepatocytes. 
(A)

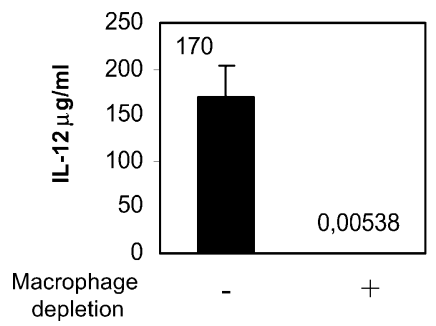

(B)

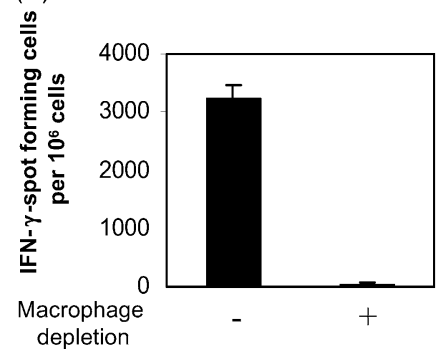

(C)

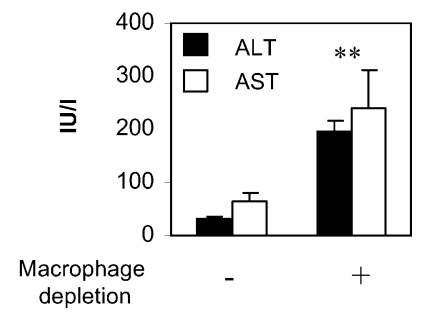

Fig. 5. Effect of macrophage depletion on the immune response induced after PEI-pgp120 administration. A group of three BALB/c mice were intravenously injected with clodronate containing liposomes; $24 \mathrm{~h}$ later, treated and untreated mice were immunized with $100 \mu \mathrm{g}$ of PEI-pgp120 via tail vein. (A) Six hours later, blood from each mouse was collected and IL-12 serum level analyzed by ELISA individually. (B) Two weeks after immunization, splenic lymphocytes were isolated and the number of IFN- $\gamma$-secreting p18-specific CD8 cells was determined by an ELISPOT assay. (C) The sera obtained $6 \mathrm{~h}$ after the administration of PEI-DNA complexes were analyzed to test the presence of liver injury marker ALT ( $\square$ ), AST ( $\square$ ). UI, international units. Significantly different from non-depleted mice $* * p<0.01$.

\section{Discussion}

The primary observation from this study is that intravenous administration of PEI-DNA complexes induces a strong innate immune response, with high levels of IL-12 and IFN- $\gamma$ expression within $6 \mathrm{~h}$ of administration. Furthermore, an administration of PEI-DNA complex expressing a viral antigen induces a generation of a strong antigen-specific cellular immune response and systemic and mucosal protection against a viral challenge.

DNA vaccination that can induce both cellular and humoral immune responses has become an attractive strategy for combating infectious diseases that require such responses for clearance, such as HIV, malaria, viral hepatitis or tuberculosis. Unfortunately, clinical trials have shown the limited efficacy of DNA vaccination in human volunteers, which necessitates the identification of technologies that can enhance DNA vaccines [20,21]. Among the strategies being evaluated to increase the efficiency of DNA vaccination is the use of non-viral vectors to deliver the DNA. One such vector, PEI 22 , has been previously described to efficiently deliver reporter genes in vivo, with particularly high expression in the lungs and lower expression in other organs like the spleen, kidney and liver [34]. Here, we show that PEI22-DNA complex shortly $-6 \mathrm{~h}$-after intravenous injection, induces high levels of IL-12 and IFN- $\gamma$ in the serum. Analysis of the expression of both cytokines in different organs of the mice that have received a single dose of PEI-DNA complexes showed high levels of IL-12 in the liver and kidney and high levels of IFN- $\gamma$ in the spleen, but low levels of these cytokines in the lungs. These cytokine expression patterns do not correlate with the pattern of in vivo transgene expression.

Intravenous administration of PEI-pgp120 induced dose dependently a gp120-specific CD8+ T cell response, and the optimal response was obtained after immunization with $100 \mu \mathrm{g}$ of the plasmid. When we determined the relative number of gp120-specific CD8+ T cells that secrete IFN- $\gamma$ by an ELISPOT assay, we found that a single dose of intravenous immunization with $100 \mu \mathrm{g}$ of PEI-gp120 could elicit a 20times higher number of gp120-specific CD8+ T cells than that elicited by three doses of intramuscular immunization with $100 \mu \mathrm{g}$ of pgp120 DNA vaccine. The number of gp120specific CD8+ T cells elicited by a single immunizing dose of PEI-pgp120 was comparable to that induced in mice vaccinated intraperitoneally with the vaccinia-gp120 vector, a well known immunizing agent [36].

Vaccines capable of protecting against sexually transmitted infections, such as human immunodeficiency virus, will depend on the induction of potent systemic and mucosal responses [13]. Therefore, we evaluated the level of protective mucosal and systemic response elicited in PEI-DNA immunized mice by challenging the mice intranasally and intraperitoneally with a sublethal dose of a recombinant vaccinia virus expressing gp120 antigen and monitoring viral loads. A single dose of PEI-pgp120 vaccine vector afforded a significant degree of protection against a vaccinia-gp120 challenge regardless of the route the virus was administered. These results indicate that a systemic administration of PEI-DNA complex can elicit strong mucosal and systemic protective responses.

Although side-effects associated with PEI-DNA complex administration have been reported, the evidence is still contradictory [34]. This has been mainly due to the use of PEIs with different molecular weights, structures and chemical modifications, and to the use of different nitrogen/phosphate ratios. In our study, the PEI used has a molecular weight of $22 \mathrm{kDa}$, is linear with no modifications and has a N/P ratio of 4 . We did not observe any morbidity and mortality when we administered the dose that could induce an optimal level of both $\mathrm{CD} 8+\mathrm{T}$ cell response and protection against viral challenge. Only when the amounts of the administered plasmid were very high, i.e. $125-150 \mu \mathrm{g}$, did we detect a toxic effect on the liver, as indicated by the increase in the serum levels of ALT and AST, and in fact when PEI-DNA-associated toxicity did occur, the result was the inhibition of the immune response.

The main sources of IL-12 are macrophages and dendritic cells. High serum levels of IL-12 observed in mice $6 \mathrm{~h}$ after PEI-DNA immunization suggest that PEI-DNA complex may target macrophages and/or dendritic cells soon after i.v. administration. Here, we show that selective in vivo depletion of macrophages using liposome-encapsulated clo- 
dronate, a widely accepted approach to deplete macrophages, completely abolished IL-12 production, as well as gp120specific CD8+ T cell response, after PEI-DNA administration. Our data indicate that macrophages mediate IL-12 production following PEI-DNA complex immunization, resulting in enhanced systemic and mucosal immune responses.

In this paper, we show that PEI is likely to act as a powerful adjuvant to generate high levels of antigen-specific immune response. Most of the currently available adjuvants approved for humans fail to enhance cellular immune responses against an antigen, while others that do enhance cellular immune response have associated side-effects that make them unsuitable for human use [37]. We have demonstrated that a single immunizing dose of PEI-DNA complex is able to induce a strong cellular immune response capable of providing both systemic and mucosal protections against a viral infection. We also show that an optimal immune response can be induced by PEI-DNA vaccination without causing any toxicity. A strong advantage of PEI-DNA-based vaccine over other immunization agents, such as recombinant viruses, is that PEI-DNA immunization does not generate neutralizing antibodies to the vector, and therefore, it can be administered repeatedly. Overall, our results indicate that PEI-DNA complex is a highly efficient vector for generating a strong antigen-specific CD8+ T cell response and systemic and mucosal protective immunity. This PEI-DNA-based vaccine is, therefore, potentially an attractive candidate for the development of a successful vaccine against human pathogens.

\section{Acknowledgements}

This work was funded in part by grant from Ministerio de Ciencia y Tecnología, MCYT (SAF2002-0372) and by grant from the agreement between FIMA and the "UTE project CIMA". We thank Dr. M. Esteban and Dr. D. Rodríguez for providing pgp120 and vac-gp120. P. Berraondo is a recipient of a scholarship from FIS; J. Crettaz is a recipient of a scholarship from Gobierno de Navarra; L. Ochoa is a recipient of a scholarship from Fundación Ramón Areces; M. Vera is a recipient of a scholarship from MCYT. We thank M. Tsuji, P. Fortes and J. Schmieg for comments and discussion.

\section{References}

[1] Putkonen P, Thorstensson R, Ghavamzadeh L. Prevention of HIV-2 and SIVsm infection by passive immunization in cynomolgus monkeys. Nature 1991;352:436-8.

[2] Emini EA, Schleif WA, Nunberg JH. Prevention of HIV-1 infection in chimpanzees by gp120 V domains-specific monoclonal antibody. Nature 1992;355:728-30.

[3] Conley AJ, Kessler II JA, Boots LJ. The consequence of passive administration of an anti-human immunodeficiency virus type 1 neutralizing monoclonal antibody before challenge of chimpanzees with a primary virus isolate. J Virol 1996;70:6751-8.

[4] McMichael AJ, Rowland-Jones SL. Cellular immune response to HIV. Nature 2001;410:980-7.
[5] Borrow P, Lewicki H, Hahn BH, Shaw GM, Oldstone MB. Virusspecific CD8+ cytotoxic T-lymphocyte activity associated with control of viremia in primary human immunodeficiency virus type 1 infection. J Virol 1994;9:6103-10.

[6] Jin X, Bauer DE, Tuttleton SE, Lewin S, Gettie A, Blanchard J, et al. Dramatic rise in plasma viremia after CD8(+) T cell depletion in simian immunodeficiency virus-infected macaques. J Exp Med 1999;189:991-8.

[7] Schmitz JE, Kuroda MJ, Santra S, Sasseville VG, Simon MA, Lifton $\mathrm{MA}$, et al. Control of viremia in simian immunodeficiency virus infection by CD8+ lymphocytes. Science 1999;283:857-60.

[8] Seth A, Ourmanov I, Schmitz JE, Kuroda MJ, Lifton MA, Nickerson $\mathrm{CE}$, et al. Immunization with a modified vaccinia virus expressing simian immunodeficiency virus (SIV) Gag-Pol primes for an anamnestic Gag-specific cytotoxic T-lymphocyte response and is associated with reduction of viremia after SIV challenge. J Virol 2000;74:2502-9.

[9] Amara RR, Villinger F, Altman JD, Lydy SL, O'Neil SP, Staprans SI, et al. Control of a mucosal challenge and prevention of AIDS by a multiprotein DNA/MVA vaccine. Science 2001;292:69-74.

[10] Barouch DH, Kunstman J, Kuroda MJ, Schmitz JE, Santra S, Peyerl $\mathrm{FW}$, et al. Eventual AIDS vaccine failure in a reshus monkey viral scape from cytotoxic lymphocytes. Nature 2002;415:335-9.

[11] Matano T, Shibata R, Siemon C, Connors M, Lane HC, Martin MA. Administration o fan anti-CD8 monoclonal antibody interfers with the clearance of chimeric simian/human immunodeficiency virus during primary infections of rhesus macaques. J Virol 1998;57: $265-6$.

[12] Lifson JD, Rossio JL, Piatak M Jr, Parks T, Li L, Kiser R, et al. Role of CD8(+) lymphocytes in control of simian immunodeficiency virus infection and resistance to rechallenge after transient early antiretroviral treatment. J Virol 2001;75:10187-99.

[13] McMichael A, Mwau M, Hanke T. Design and test of an HIV vaccine. Br Med Bull 2002;62:87-98.

[14] Barouch DH, Santra S, Schmitz JE, Kuroda MJ, Fu TM, Wagner W, et al. Control of viremia and prevention of clinical AIDS in rhesus monkeys by cytokine-augmented DNA vaccination. Science 2000;290:486-92.

[15] Barouch DH, Santra S, Tenner-Racz K, Racz P, Kuroda MJ, Schmitz $\mathrm{JE}$, et al. Potent CD4+ $\mathrm{T}$ cell response elicited by a bicistronic HIV-1 DNA vaccine expressing gp120 and GM-CSF. J Immunol 2002;168:562-8.

[16] Santra S, Barouch DH, Jackson SS, Kuroda MJ, Schmitz JE, Lifton $\mathrm{MA}$, et al. Functional equivalency of B7-1 and B7-2 for costimulating plasmid DNA vaccine-elicited CTL responses. J Immunol 2000;165:6791-5.

[17] Oh S, Berzofsky JA, Burke DS, Waldman T, Perera LP. Coadministration of HIV vaccine vectors with vaccinia viruses expressing IL-15 but not IL-2 induces long-lasting cellular immunity. Proc Natl Acad Sci USA 2003;100:3392-7.

[18] Donnelly JJ, Ulmer JB, Shiver JW, Liu MA. DNA vaccines. Annu Rev Immunol 1997;15:617-48.

[19] Ulmer JB, Donnelly JJ, Parker SE, Rhodes GH, Felgner PL, Dwarki VJ, et al. Heterologous protection against influenza by injection of DNA encoding a viral protein. Science 1993;259:1745-9.

[20] Wang R, Epstein J, Baraceros FM, Gorak EJ, Charoenvit Y, Carucci $\mathrm{DJ}$, et al. Induction of $\mathrm{CD} 4(+) \mathrm{T}$ cell-dependent CD8(+) type 1 responses in humans by a malaria DNA vaccine. Proc Natl Acad Sci USA 2001;98:10817-22.

[21] MacGregor RR, Boyer JD, Ugen KE, Lacy KE, Gluckman SJ, Bagarazzi ML, et al. First human trial of a DNA-based vaccine for treatment of human immunodeficiency virus type 1 infection: safety and host response. J Infect Dis 1998;178:92-100.

[22] Liu MA. DNA vaccines: a review. J Int Med 2003;253:402-10.

[23] Luhrs P, Schmidt W, Kutil R, Buschle M, Wagner SN, Stingl G, et al. Induction of specific immune responses by polycation-based vaccines. J Immunol 2002;169:5217-26. 
[24] Boussif O, Lezoualch F, Zanta MD, Mergny D, Scherman D, Demeneix B, et al. A versatile vector for gene and oligonucleotide transfer into cells in culture and in vivo: polyethylenimine. Proc Natl Acad Sci USA 1995;92:7297-301.

[25] Bieber T, Meissner W, Kostin S, Niemann A, Elsasser HP. Intracellular route and transcriptional competence of polyethylenimine-DNA complexes. J Contr Rel 2002;82:441-54.

[26] Wightman L, Kircheis R, Rössler V, Carotta S, Ruzicka R, Kursa $\mathrm{M}$, et al. Different behavior of branched and linear polyethyleimine for gene delivery in vitro and in vivo. J Gen Med 2001;3:362-72.

[27] Oh YK, Kim JP, Kim Yoon H, Kim JM, Yang JS, Kim CM. Prolonged organ retention and safety of plasmid DNA administered in polyethylenimine complexes. Gen Ther 2001;8:1587-92.

[28] Ferrari S, Pettenazzo A, Garbati N, Zacchello F, Behr JP, Scarpa M. Polyethylenimine shows properties of interest for cystic fibrosis gene therapy. Biochim Biophys Acta 1999;1447:219-25.

[29] Orson FM, Kinsey BM, Hua PJ, Bhogal BS, Densmore CL, Barry MA. Genetic immunization with lung-targeting macroaggregated polyethyleneimine-albumin conjugates elicits combined systemic and mucosal immune responses. J Immunol 2000;164:6313-21.

[30] Carvalho LH, Hafalla JC, Zavala F. ELISPOT assay to measure antigen-specific murine CD8(+) T cell responses. J Immmunol Meth $2001 ; 252: 207-18$
[31] Van Rooijen N, Sanders A. Liposome mediated depletion of macrophages: mechanism of action, preparation of liposomes and applications. J Immunol Meth 1994;174:83-93.

[32] Van Rooijen N, Sanders A, Van den Berg TK. Apoptosis of macrophages induced by liposome-mediated intracellular delivery of clodronate and propamidine. J Immunol Meth 1996;193:939.

[33] Sato Y, Roman H, Tighe D, Lee D, Corr M, Nguyen MD, et al. Immunostimulatory DNA sequences necessary for effective intradermal gene immunization. Science 1996;273:352-4.

[34] Chollet P, Favrot MC, Hurbin A, Coll JL. Side-effects of a systemic injection of linear polyethylenimine-DNA complexes. J Gen Med 2002;4:84-91.

[35] Shirin H, Bruck R, Aeed H, Hershkoviz R, Lider O, Kenet G, et al. Effects of intravenous immunoglobulins on T-cell mediated, concanavalin A-induced hepatitis in mice. Liver 1997;17:27580.

[36] Zavala F, Rodrigues M, Rodriguez D, Rodríguez JR, Nussenzweig RS, Esteban M. A striking property of recombinant poxviruses: ef ficient inducers of in vivo expansion of primed CD8(+) T cells. Virology 2001;280:155-9.

[37] Singh M, O'Hagan D. Advances in vaccine adjuvants. Nat Biotechnol 1999;17:1075-81. 